\title{
SIMULATION BASED TRAINING IMPROVES LAPAROSCOPIC SURGICAL SKILLS IN TRAINEE SURGEONS
}

\author{
Abdul Razaque Shaikh, Tanwir Khaliq* \\ Sir Syed College of Medical Sciences for Girls, Karachi Pakistan, *Shaheed Zulfiqar Ali Bhutto Medical University, Islamabad Pakistan
}

\begin{abstract}
Objective: To assess the impact of laparoscopic simulation training on surgical skills of trainee surgeons.

Study Design: Comparative prospective study.

Place and Duration of Study: Jinnah Sindh Medical University Karachi, for one month October 2019.

Methodology: Total thirty surgical trainees of FCPS year four (R4) were studied. The cases group (fifteen trainees) were given one month laparoscopy training on a LAP Simulator (LAPSim), surgical science Sweden) and the control group (fifteen trainees) were not trained. Their laparoscopic skills were then compared. Objective Structured Assessment of Technical Skills (OSATS) specific and general was used to assess their performance. Data was entered and analyzed using SPSS-23.

Results: On LAP Sim Scoring, post-test scores were significantly better than pre-test for all skills in the trained residents $(p<0.01$ for all subscales) and total post-test score was also significantly better for trained surgeons as compared to untrained $(77.45 \pm 7.78$ vs. $31.70 \pm 2.48 ; p<0.01)$. On Objective Structured Assessment of Technical Skills for specific tasks, post-test scores were significantly better than pre-test for all tasks in the cases $(p<0.01$ for all subscales) and for none in the controls. On Objective Structured Assessment of Technical Skills general, posttest scores were significantly better than pre-test for all tasks in the cases $(p<0.01$ for all subscales) and for clip application $(p<0.01)$ and suturing with intracorporeal knot tying $(p<0.01)$ in the controls.

Conclusion: This study demonstrated significantly improved levels of performance for all skill sets for novice surgical residents trained on LAP Sim for minimally invasive surgical procedures.
\end{abstract}

Keywords: Laparoscopy, LAP sim, Medical education, Simulation based training, Surgical performance, Surgical skills, Virtual reality.

This is an Open Access article distributed under the terms of the Creative Commons Attribution License (http://creativecommons.org/licenses/by/4.0), which permits unrestricted use, distribution, and reproduction in any medium, provided the original work is properly cited.

\section{INTRODUCTION}

Surgical residents are mostly trained within the operation theatres by expert surgeons under the mentor-apprenticeship model ${ }^{1}$. This method was effective for open surgical procedures. However, with the advent of laparoscopic surgery, surgical expert as well as trainees faced new challenges in terms of lack of tactile feedback, increased distance from the surgical field, and difference in the perception of depth due to two dimensional imaging. Hence, surgical complications became more frequent with laparoscopic procedures and most complications were related to the skills of the surgeon such as bile duct injury during laparoscopic cholecystectomy2. These frequent complications and consequent concerns

Correspondence: Dr Abdul Razaque Shaikh, Apt 302, Al-Habib Residency, Reay Road, Civil Lines, Karachi Pakistan

Received: 06 Jan 2020; revised received: 11 Mar 2020; accepted: 20 Apr 2020 regarding the safety of laparoscopic procedures led to simulation for laparoscopic surgery training outside of the operation theatre ${ }^{3}$.

The various models for learning laparoscopic skills are physical box trainers, virtual reality simulators, animal models, cadavers, and patients ${ }^{4}$. Another effective and widely used model is the LAP Sim simulator. Learning laparoscopic skills on a lap mentor is a standard training accepted globally. It provides a proficient and specialized environment for training and practice without putting in any burden to the patient safety. Through simulation training, expert surgeons recreate real-time experiences for trainees to practice and enhance their skills. Simulation-based laparoscopic surgery training has large benefits when compared with no intervention and is more effective than non-simulation. Simulation has been established to be an efficient, feasible, and useful 
method to prepare surgical trainees for more complex and advance procedures ${ }^{5}$. Furthermore, laparoscopic training is also not a one-time thing. Laparoscopic skills rapidly deteriorate without repeated training on lap simulation. In a cohort with novice surgeon trainees, retention of skills was seen after 6 months of training and skills returned to the pre-training level after 18 months $^{6}$. In a local report from Jamshoro, longer operating time, $11 \%$ postoperative complications, and $6 \%$ conversion rate was reduced for laparoscopic procedures done with no prior training on lapsimulator ${ }^{3}$. In Pakistan, most of postgraduate training programs are monitored by the College of Physicians and Surgeons Pakistan (CPSP). According to CPSP, trainees of four-year general surgery programs should be adequately trained in terms of laparoscopic skills by expert laparoscopic surgeons along with conventional open surgical skills. Hence, we conducted a study with trainee surgeons to assess the effects of laparoscopic simulation training on their surgical skills.

\section{METHODOLOGY}

A comparative prospective study was initiated with fourth year residents (R4) of FCPS General Surgery undergoing training in Jinnah Postgraduate Medical Centre Karachi. The study was approved by the institutional review board of Jinnah Sindh Medical University (JSMU) JSMU /IRB/2019/-221.

Sample size was estimated by using Open Epi online sample size calculator. Mean OSATS score was taken as $19.3 \pm 5.1$ after first session and as $24.4 \pm 2.2$ after second session ${ }^{7}$. With a power of test as taken $90 \%$ and $95 \%$ confidence level, the estimated sample size was 13 but for our study we included 15 in each group respectively. Fifteen participants were included in both groups after attaining informed consent for one month (October 2019). Residents who refused to participant were excluded.

All participants were randomly coded and allotted to one of the two study groups. The test/ case group was provided training of the following four laparoscopic surgery tasks: (i) lifting and grasping, (ii) cutting, (iii) clip application, (iv) and suturing with intracorporeal knot tying at a Lap Sim (figure) for one month daily for 45 minutes under supervision of the principal investigator (surgeon) and another consultant General Surgeon. The control group was not trained for the study. No participants had received any formal training at a lap simulator before this study.

Performance was assessed by obtaining results directly from the LAP Sim Software. Objective Structured Assessment of Technical Skills (OSATS) was utilized for direct observation of residents' skills by expert surgeons. OSATS comprises on two sub-scales. OSATS has been previously validated for evaluation of a prog$\mathrm{ram}^{8}$. OSATS were used as follows in the study: The score for OSATS STS ranges from 0-16, for OSATS GRS from 1-20, and for LAP Simscore is measured in percentages ranging from $0-100 \%$.

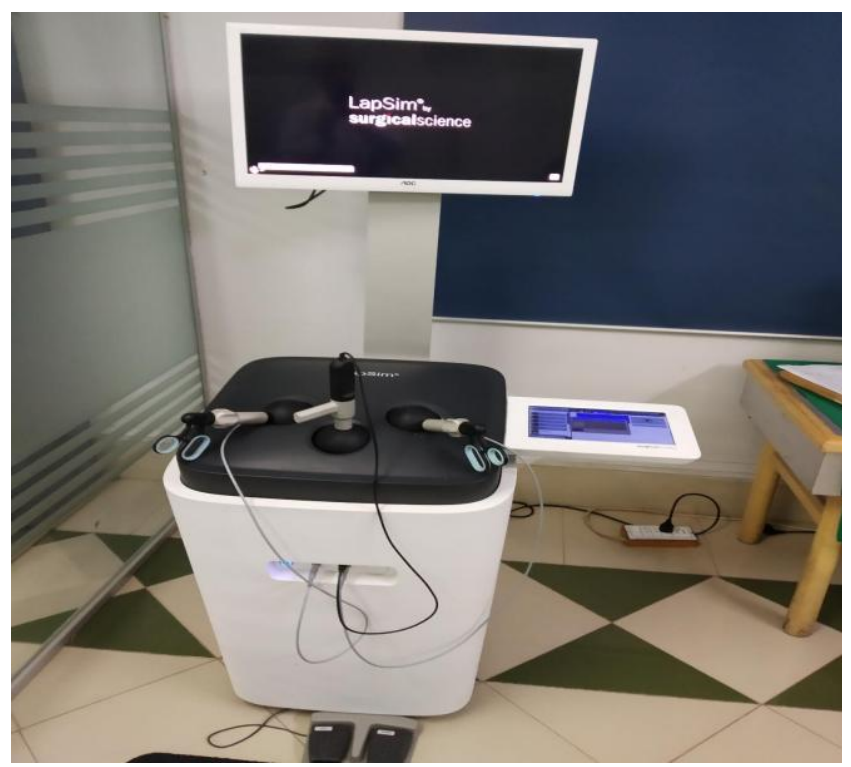

Figure-1: Lap simulator used in this study is model lap sim, brand is surgical science and manufactured in sweden.

For all study participants, OSATS STS, OSATS GRS, and LAP Sim scores were collected at two intervals. For cases, first scores were collected before one-month training (pre-test score) and second scores after training (post-test score). For controls, both scores were collected one month apart but without any training and were also called pre-test and post-test scores. For con- 
sistency, OSATS scores were collected under direct observation of two consultant general surgeons who also supervised LAP Sim Simulator training.

Data were stored and analyzed using IBMSPSS version 23.0. Mean and standard deviation (SD) were given for LAP Mentoring, OSAT STS and OSAT GRS for trained and untrained groups at pre-and-post-test stages. Independent sample

\section{RESULTS}

Sixty performances were recorded in this study out of which thirty were pre-test and thirty post-test. Mean pre-test and post-test LAP Sim scores for both cases and controls were summarized in table-II. Within group analysis using paired sample t-test showed there was significant mean difference in pre-test and post-test scores for all LAP Sim scoring components among

Table-I: Objective structured assessment of technical skills (OSATS) specific technical skills (STS) and global rating scale (GRS).

Objective Structured Assessment of Technical Skills (OSATS) Specific Technical Skills (STS) Scale

\begin{tabular}{|c|c|c|}
\hline Specific Task & Yes & No \\
\hline \multicolumn{3}{|l|}{ Cutting } \\
\hline Grasps the object using the grasper & 1 & 0 \\
\hline $\begin{array}{l}\text { Stretches the vessel sufficiently before } \\
\text { cutting the vessel }\end{array}$ & 1 & 0 \\
\hline $\begin{array}{l}\text { Does not damages the vessel by } \\
\text { overstretching }\end{array}$ & 1 & 0 \\
\hline Cuts using the ultrasonic scissor & 1 & 0 \\
\hline \multicolumn{3}{|l|}{ Clip Application } \\
\hline $\begin{array}{l}\text { Stretches the vessel tip gently with } \\
\text { grasper so that demarcated area appears }\end{array}$ & 1 & 0 \\
\hline $\begin{array}{l}\text { Applies the clips on two demarcated } \\
\text { areas with clip applicator }\end{array}$ & 1 & 0 \\
\hline $\begin{array}{l}\text { Applies clips properly so that vessel is not } \\
\text { damaged }\end{array}$ & 1 & 0 \\
\hline Cuts the vessel between clips with scissor & 1 & 0 \\
\hline \multicolumn{3}{|l|}{ Lifting and Grasping } \\
\hline $\begin{array}{l}\text { Lifts the object from bellow with one } \\
\text { hand }\end{array}$ & 1 & 0 \\
\hline $\begin{array}{l}\text { Moves the needle at the same time with } \\
\text { other hand with grasper }\end{array}$ & 1 & 0 \\
\hline Puts the needle in a bucket properly & 1 & 0 \\
\hline $\begin{array}{l}\text { Extracts the needle properly if dropped } \\
\text { without organ damage }\end{array}$ & 1 & 0 \\
\hline \multicolumn{3}{|l|}{ Simple Suture with Intracopreal Knot } \\
\hline Places a simple stitch on demarcated area & 1 & 0 \\
\hline Ties first knot & 1 & 0 \\
\hline Ties second knot & 1 & 0 \\
\hline Ties the knots securely and properly & 1 & 0 \\
\hline
\end{tabular}

t-test was used to compare theses scores between groups whereas paired sample t-test was used to compare these scores within groups (pre-andpost-test comparison). The $p$-values $\leq 0.05$ were considered significant.

\begin{tabular}{|c|c|c|c|c|}
\hline \multicolumn{5}{|c|}{ Objective Structured Assessment of Technical Skills } \\
\hline \multicolumn{5}{|c|}{ Tissue and Instrument Handling } \\
\hline $\begin{array}{l}\text { 1. Rough } \\
\text { movements; } \\
\text { awkward } \\
\text { handling of } \\
\text { instruments } \\
\text { and tissue } \\
\text { (or model) }\end{array}$ & 2. & $\begin{array}{l}\text { 3. Careful } \\
\text { handling of } \\
\text { instruments } \\
\text { and tissue } \\
\text { (or model) } \\
\text { overall, with } \\
\text { occasional } \\
\text { awkward } \\
\text { movements }\end{array}$ & 4. & $\begin{array}{l}\text { 5. Consistently } \\
\text { appropriate } \\
\text { and careful } \\
\text { handling of } \\
\text { instruments } \\
\text { and tissue (or } \\
\text { model) }\end{array}$ \\
\hline \multicolumn{5}{|c|}{ Depth Perception/Accuracy } \\
\hline $\begin{array}{l}1 . \\
\text { Constantly } \\
\text { misses } \\
\text { target, slow } \\
\text { to correct }\end{array}$ & 2. & $\begin{array}{c}\text { 3. } \\
\text { Sometimes } \\
\text { misses } \\
\text { target, quick } \\
\text { to correct }\end{array}$ & 4. & $\begin{array}{l}\text { 5. Accurately } \\
\text { directs } \\
\text { instrument to } \\
\text { target }\end{array}$ \\
\hline \multicolumn{5}{|c|}{ Dexterity/Efficiency } \\
\hline $\begin{array}{l}1 . \\
\text { Uncertain, } \\
\text { inefficient } \\
\text { movements } \\
\text { without } \\
\text { progress }\end{array}$ & 2. & $\begin{array}{l}\text { 3. Efficient } \\
\text { movements } \\
\text { overall with } \\
\text { some } \\
\text { unnecessary } \\
\text { moves }\end{array}$ & 4. & $\begin{array}{c}\text { 5. Fluid, } \\
\text { efficient } \\
\text { movements } \\
\text { without } \\
\text { wasted time } \\
\text { or motion }\end{array}$ \\
\hline \multicolumn{5}{|c|}{ Autonomy (Proficiency) } \\
\hline $\begin{array}{l}\text { 1. Unable to } \\
\text { complete } \\
\text { entire task } \\
\text { at this time }\end{array}$ & 2. & $\begin{array}{l}\text { 3. Able to } \\
\text { perform } \\
\text { task safely } \\
\text { with some } \\
\text { instruction }\end{array}$ & 4. & $\begin{array}{c}\text { 5. Able to } \\
\text { perform task } \\
\text { safely \& } \\
\text { independently } \\
\text { without } \\
\text { instruction }\end{array}$ \\
\hline
\end{tabular}

trained samples and only significant difference observed in pre-test and post-test total score for untrained samples $(p \leq 0.05)$. Between groups analyses using independent sample t-test showed there was significant mean difference for all com- 
ponents of LAP Sim scoring between trained and untrained samples $(p \leq 0.05)$. However, no significant mean difference observed of these component scores at pre stage between trained and untrained samples $(p>0.05)$ (table-II). summarized in table-III. Within group analysis using paired sample t-test showed there was significant mean difference in pre-test and posttest scores for all laparoscopic tasks on OSATS STS among trained samples $(p \leq 0.05)$, although,

Table-II: Mean comparison of LAPSIM scoring using t-test.

\begin{tabular}{|c|c|c|c|c|c|c|}
\hline \multirow{3}{*}{ LAPSIM Scoring \% } & \multirow{3}{*}{ Stages } & \multicolumn{4}{|c|}{ Group } & \multirow{3}{*}{$p$-value } \\
\hline & & \multicolumn{2}{|c|}{ Trained $(n=15)$} & \multicolumn{2}{|c|}{ Untrained (n=15) } & \\
\hline & & Mean & SD & Mean & SD & \\
\hline \multirow{2}{*}{ Lifting and Grasping } & Pre-test & $29.13^{* *}$ & 5.25 & 30.13 & 4.32 & 0.21 \\
\hline & Post-test & 76.13 & 8.26 & 29.13 & 5.25 & $<0.01^{*}$ \\
\hline \multirow{2}{*}{ Cutting } & Pre-test & $37.73^{* *}$ & 3.75 & 35.40 & 4.22 & 0.42 \\
\hline & Post-test & 81.40 & 7.29 & 37.73 & 3.75 & $<0.01^{*}$ \\
\hline \multirow{2}{*}{ Clip Application } & Pre-test & $36.80^{* *}$ & 3.63 & 36.40 & 3.62 & 0.12 \\
\hline & Post-test & 74.13 & 7.24 & 36.80 & 3.63 & $<0.01^{*}$ \\
\hline \multirow{2}{*}{$\begin{array}{l}\text { Suturing with } \\
\text { intracorporeal knot tying }\end{array}$} & Pre-test & $23.13^{* *}$ & 3.50 & 21.13 & 2.64 & 0.15 \\
\hline & Post-test & 73.10 & 8.20 & 23.13 & 3.50 & $<0.01^{*}$ \\
\hline \multirow{2}{*}{ Total } & Pre-test & $31.70^{* *}$ & 2.48 & $30.77^{* *}$ & 1.66 & 0.23 \\
\hline & Post-test & 77.45 & 7.78 & 31.70 & 2.48 & $<0.01^{*}$ \\
\hline
\end{tabular}

${ }^{*}$ Considered significant using independent sample $\mathrm{t}$-test between groups $p<0.05,{ }^{* *}$ Considered significant using paired $\mathrm{t}$-test within group $p<0.05$

Table-III: Mean comparison of OSATSS pecific task scoring using t-test.

\begin{tabular}{|c|c|c|c|c|c|c|}
\hline \multirow{4}{*}{$\begin{array}{l}\text { OSATSS Pecific Task } \\
\text { Score }\end{array}$} & \multirow{4}{*}{ Stages } & \multirow{2}{*}{\multicolumn{4}{|c|}{ Group }} & \multirow{4}{*}{$p$-value } \\
\hline & & & & & & \\
\hline & & \multicolumn{2}{|c|}{ Trained $(n=15)$} & \multicolumn{2}{|c|}{ Untrained (n=15) } & \\
\hline & & Mean & SD & Mean & SD & \\
\hline \multirow{2}{*}{ Lifting and Grasping } & Pre-test & $1.80^{* *}$ & 0.25 & 1.93 & 0.32 & 0.21 \\
\hline & Post-test & 3.10 & 0.21 & 1.90 & 0.43 & $<0.01^{*}$ \\
\hline \multirow{2}{*}{ Cutting } & Pre-test & $1.87^{* *}$ & 0.35 & 1.77 & 0.32 & 0.42 \\
\hline & Post-test & 3.00 & 0.19 & 1.87 & 0.48 & $<0.01^{*}$ \\
\hline \multirow{2}{*}{ Clip Application } & Pre-test & $1.93^{* *}$ & 0.32 & 1.73 & 0.37 & 0.12 \\
\hline & Post-test & 3.17 & 0.24 & 1.77 & 0.26 & $<0.01^{*}$ \\
\hline \multirow{2}{*}{$\begin{array}{l}\text { Suturing with } \\
\text { intracorporeal knot tying }\end{array}$} & Pre-test & $1.33^{* *}$ & 0.36 & 1.17 & 0.24 & 0.15 \\
\hline & Post-test & 3.83 & 0.24 & 1.37 & 0.77 & $<0.01^{*}$ \\
\hline
\end{tabular}

${ }^{*}$ Considered significant using independent sample $\mathrm{t}$-test between groups $p<0.05,{ }^{* *}$ Considered significant using paired $\mathrm{t}$-test within group $p<0.05$

Table-IV: Mean comparison of OSATS global scoring using t-test.

\begin{tabular}{|c|c|c|c|c|c|c|}
\hline \multirow{3}{*}{ OSATS Global Score } & \multirow{3}{*}{ Stages } & \multicolumn{4}{|c|}{ Group } & \multirow{3}{*}{$p$-value } \\
\hline & & \multicolumn{2}{|c|}{ Trained $(n=15)$} & \multicolumn{2}{|c|}{ Untrained $(n=15)$} & \\
\hline & & Mean & SD & Mean & SD & \\
\hline \multirow{2}{*}{ Lifting and Grasping } & Pre-test & $12.80^{* *}$ & 0.32 & 7.70 & 0.49 & $<0.01^{*}$ \\
\hline & Post-test & 17.77 & 0.37 & 7.83 & 0.31 & $<0.01^{*}$ \\
\hline \multirow{2}{*}{ Cutting } & Pre-test & $12.67^{* *}$ & 0.49 & 7.63 & 0.55 & $<0.01^{*}$ \\
\hline & Post-test & 17.27 & 0.37 & 7.77 & 0.53 & $<0.01^{*}$ \\
\hline \multirow{2}{*}{ Clip Application } & Pre-test & $12.37^{* *}$ & 0.23 & $7.20^{* *}$ & 0.53 & $<0.01^{*}$ \\
\hline & Post-test & 17.26 & 0.36 & 7.73 & 0.46 & $<0.01^{*}$ \\
\hline \multirow{2}{*}{$\begin{array}{l}\text { Suturing with } \\
\text { intracorporeal knot tying }\end{array}$} & Pre-test & $6.77^{* *}$ & 0.37 & $6.63^{* *}$ & 0.72 & 0.52 \\
\hline & Post-test & 16.83 & 0.31 & 7.27 & 0.42 & $<0.01^{*}$ \\
\hline
\end{tabular}

The mean pre-test and post-test scores of OSATS STS for both cases and controls are none of the component was significant at pre-test and post-test for untrained samples. Between 
group analyses using independent sample t-test showed there was significant mean difference for all components of OSAT specific tasks between trained and untrained samples $(p \leq 0.05)$ (table-III).

The mean pre-test and post-test scores of OSATS GRS for both cases and controls were summarized in table-IV. Within group analysis using paired sample t-test showed there was significant mean difference in pre-test and posttest scores for all tasks on OSATS GRS among trained samples $(p \leq 0.05)$ and clip application and suturing with intracorporeal knot tying scores was significant mean difference at pre-test and post-test for untrained samples $(p \leq 0.05)$. Between group analyses using independent sample t-test showed there was significant mean difference for all components of OSATS GRS tasks between trained and untrained samples $(p \leq 0.05)$ except pre-test suturing with intracorporeal knot tying scores found statistically insignificant between two groups (table-IV).

In reliability analysis, the intraclass correlation analysis was done to see the correlation between rater-I and rater-II observations, results showed, there was $84.3 \%$ significant positive correlation for lifting and grasping scoring, 85.3\% Significant positive correlation for cutting, $82.0 \%$ significant positive correlation for clip application and $95.5 \%$ significant positive correlation for suturing with intracorporeal knot tying scoring between rater-I and rater-II observations. $p<0.01$. The Cronbach's alpha for OSAT was 0.953 , and for global scale it was 0.998 .

\section{DISCUSSION}

The basic purpose of this interventional study was to focus on the performance outcomes of simulation based training as compared to training at all. The present study demonstrated that training on LAP Sim simulators improved laparoscopic skills of trainee surgeons. On LAP Sim and OSATS STS, surgeons who were trained scored better than the controls on all skills. On OSATS GRS, trained surgeons scored significantly better after training on all parameters and untrained surgeons scored better for clip application and suturing with intracorporeal knot tying after one month, although no formal training was provided to them for this study.

Simulation based training has offered great opportunities in terms of laparoscopic skills practice outside the environment of an operating room and without burdening the patients. Simulation based training modalities help the surgical trainees in obtaining necessary sets of surgical skills required for minimally invasive surgeries before implementing them on real patients. Simulation based training environment is stress-free and comfortable for the trainees to practice in 9 . As per the literature, the most effective virtual reality (VR) simulator for surgical training has been LAP Sim. Many other multimodality trainers are being used and data has been published for them too, but as a single modality learning tool LAP Sim has shown the efficiency of completely incorporating the laparoscopic training curriculum in itself. It has provided similar levels of trainee performance as any other multi-modality training tool ${ }^{10,11}$.

The results of our study demonstrated significantly improved levels of performance for all skill sets for novice surgical residents trained on LAP Sim for minimally invasive surgical procedures. These results were in alignment with previous observational and interventional studies conducted to assess the role of VR based surgical training7,12-15. In Buescher et al, (2017), there was significant decrease in operation time $(p<0.01)$ at the time of training and also after six weeks indicating skill retention ${ }^{12}$. Fu et al, (2015) concluded that specialized training courses improved surgeon's familiarity with the procedures, reduced operation time and risk, and improved safety ${ }^{13}$. Paquette et al, (2017), was a comparative study which deduced that junior trainees significantly improved their speed of execution, accuracy, and maintenance of horizontal view with virtual simulators and the senior trainees accelerated their rapidity in completing different tasks ${ }^{14}$.

In a detailed systematic analysis of 219 published studies, it was demonstrated with when 
compared to no intervention, simulation based training group showed better outcomes of knowledge, skills time, skills process, skills product, behavior time, behavior process, and patient effects. All differences were statistically significant. Even when non-simulation instructions were compared with simulations, the results were significantly better for simulation group in terms of skills time and skills process ${ }^{16}$.

The idea and practice of VR based training for minimally invasive surgical procedures is not new for the global surgical community; especially in the developed world ${ }^{17}$. However, in countries with limited resources and a struggling economy, the idea is still uncommon ${ }^{18}$. In a locally published article (Sherrif et al, 2015), 46\% surgical trainees were not trained for laparoscopic procedures and only $15 \%$ had performed laparoscopic procedures independently and/or assisted ${ }^{19}$. Comparatively, results from a Canadian study revealed that $97 \%$ of their trainees were exposed to some extent of laparoscopic procedures during their residency and as many as $21 \%$ were confident about their independent laparoscopic skills by the end of their residency ${ }^{20}$. This vast discrepancy in local and international attitude towards simulation based learning is also evident from the paucity of local literature ${ }^{21}$.

To the best of our knowledge, this was the first interventional study to evaluate the role of LAP SIM in enhancing surgical skills of trainee surgeons. However, the study has its limitations too. The most evident limitation is the small sample size which doesn't allow us to generalize the results for the entire population of Pakistani surgical trainees. Secondly, due to lack of time and resources, the trained/untrained surgeons were not followed for their performance in the operating rooms, hence, this study failed to demonstrate the real-life impact of VR based training on the surgical skills of the trainees when performing laparoscopic procedures on their patients. We recommend such studies to be conducted locally and assess the real-life impact of VR based training on the efficiency and safety of minimally invasive surgical procedures.

\section{CONCLUSION}

This study demonstrated significantly improved levels of performance for all skill sets for novice surgical residents trained on LAP Sim for minimally invasive surgical procedures. Out of operation room and virtual reality based training is still not a common practice in a low resource country like Pakistan. Expert surgeons should focus more on this form of training for their surgical trainees. More local literature should be published to assess the role of VR based training on the surgical skills and its impact on the efficiency and safety of minimally invasive surgical procedures in real-life patients.

\section{CONFLICT OF INTEREST}

This study has no conflict of interest to be declared by any author.

\section{REFERENCES}

1. Aydin A, Fisher R, Khan MS, Dasgupta P, Ahmed K. Training, assessment and accreditation in surgery. Postgrad Med J 2017; 93(1102): 441-48.

2. Jung YK, Kwon YJ, Choi D, Lee KG. What is the safe training to educate the laparoscopic cholecystectomy for surgical residents in early learning curve. J Minim Invasive Surg 2016; 19(2): 70-74.

3. Ali SA, Somro AG, Mohammad AT, Jarwar M, Siddique AJ. Experience of laparoscopic cholecystectomy during a steep learning curve at a university hospital. J Ayub Med Coll Abbot 2012; 24(1): 27-29.

4. Spruit EN, Band G, Hamming GJ, Ridderinkhof KR. Optimal training design for procedural motor skills: a review and application to laparoscopic surgery. Psychol Res 2014; 78(8): 878-91.

5. Vanderbilt AA, Grover AC, Pastis NJ, Feldman M, Granados DD, Murithi LK, et al. Randomized controlled trials: a systematic review of laparoscopic surgery and simulation-based training. Global J Health Sci 2015; 7(2): 310.

6. Maagaard M, Sorensen JL, Oestergaard J, Dalsgaard T, Teodor P. Grantcharov, et al. Retention of laparoscopic procedural skills acquired on a virtual-reality surgical trainer. Surg Endosc 2011; 25(3): 722-27.

7. Schmitt F, Mariani A, Eyssartier E, Granry JC, Podevin G. Skills improvement after observation or direct practice of a simulated laparoscopic intervention. J Gynecol Obstet Hum Reproduc 2018; 47(3): 101-06

8. Hatala R, Cook DA, Brydges R, Hawkins R. Constructing a validity argument for the objective structured assessment of technical skills (OSATS): a systematic review of validity evidence. Adv Health Sci Educ 2015; 20(5): 1149-75.

9. Zafar A. Minimal access surgery in Pakistan: role of virtual reality simulation in training environment. Isra Med J 2014; 6(3): 183-84.

10. Takeda J, Kikuchi I, Kono A, Ozaki R, Kumakiri J, Takeda S. Efficacy of short-term training for acquisition of basic laparoscopic skills. Gynecol Minim Invasive Ther 2016; 5(3): 112-15.

11. Kowalewski KF, Minassian A, Hendrie JD, Benner L, Preukschas AA, Kenngott HG, et al. One or two trainees per workplace for 
laparoscopic surgery training courses: results from a randomized controlled trial. Surgical Endosc 2019; 33(5): 1523-31.

12. Buescher JF, Mehdorn AS, Neumann PA, Becker F, Eichelmann AK, Pankratius U, et al. Effect of continuous motion parameter feedback on laparoscopic simulation training: a prospective randomized controlled trial on skill acquisition and retention. J Surg Educ 2018; 75(2): 516-26.

13. Fu S, Liu X, Zhou L, Zhou M, Wang L. Applied research on laparoscopic simulator in the resident surgical laparoscopic operation technical training. Indian J Surg 2017; 79(4): 288-93.

14. Paquette J, Lemyre M, Vachon-Marceau C, Bujold E, MaheuxLacroix S. Virtual laparoscopy simulation: a promising pedagogic tool in gynecology. J Soc Laparoend 2017; 21(3): e00048S.

15. Torricelli FC, Barbosa JA, Marchini GS. Impact of laparoscopic surgery training laboratory on surgeon's performance. World J Gast Surg 2016; 8(11): 735-43.

16. Zendejas B, Brydges R, Hamstra SJ, Cook DA. State of the evi- dence on simulation-based training for laparoscopic surgery a systematic review. Ann Surg 2011; 257(4): 586-93.

17. Alaker M, Wynn GR, Arulampalam T. Virtual reality training in laparoscopic surgery: a systematic review \&meta-analysis. Int J Surg 2016; 29(1): 85-94.

18. Chao TE, Mandigo M, Opoku-Anane J, Maine R. Systematic review of laparoscopic surgery in low-and middle-income countries: benefits, challenges, and strategies. Surgical Endosc 2016; 30(1): 1-10.

19. Sheriff HM, Ghauri AU, Shalabi H, Javed IN. Laparoscopic surgery-surgical trainees' practices. J Rwp Med Coll 2015; 19 (S-1): 33-35.

20. Fazio LM, Dagnone AJ, Blew BD, Honey RJ. The laparoscopic experience of recently trained Canadian urologists. Can J Urol 2006; 13(2): 3047-52.

21. Hasan O, Iqbal S. Innovation-Medical Education. Innovat J Pak Med Assoc 2017; 67(9): 1404-09. 